\title{
Uma abordagem da dinâmica do desenvolvimento científico e tecnológico das baterias lítio-íon para veículos elétricos
}

\author{
Tatiana Bermúdez-Rodríguez* (D)
}

Flávia Luciane Consoni** (D)

* Universidade Estadual de Campinas (Unicamp), Campinas, SP, Brasil.

E-mail: ladytb@unicamp.br

** Universidade Estadual de Campinas (Unicamp), Campinas, SP, Brasil.

E-mail: fconsoni@unicamp.br

Submissão: I 3 de feVereiro de 2020 Versão reVisada (entregue): 2 I de MAio de 2020 Aprovado: 23 DE JUNHO de 2020

\section{Resumo}

O principal componente dos veículos elétricos (VE) é a sua bateria. Considerando que as baterias lítio-íon têm oferecido as melhores respostas a diferentes problemas tecnológicos, o que inclui tempo de recarga, autonomia, peso e densidade energética, questiona-se qual tem sido o seu desenvolvimento científico e tecnológico ao longo do tempo. $\mathrm{O}$ objetivo deste artigo é avançar na compreensão desta questão a partir de um estudo bibliométrico e de patentes das baterias lítio-íon para VE. Os resultados indicam que a dinâmica de publicação de artigos científicos e de famílias de patentes tem sido crescente, em especial a partir de 2009, motivada por preocupaçóes ambientais e pelo interesse de uma diversidade de empresas no crescimento deste mercado. Países asiáticos tais como Japão, China, Coreia do Sul e Taiwan, além dos Estados Unidos e algumas naçóes europeias, ocupam a liderança nesta corrida tecnológica. Um ponto de destaque são as redes de colaboração que têm se formado entre universidades com foco na publicação de artigos científicos, e entre montadoras tradicionais e empresas do setor eletroeletrônico, para atividades de patenteamento. Este movimento evidencia a necessidade da articulação e complementaridade entre diferentes áreas do conhecimento para o avanço do desenvolvimento tecnológico das baterias de lítio-íon. 
Palavras-chave | Baterias de lítio-íon; Veículos elétricos; Análise de patentes; Análise bibliométrica.

\section{AbSTRact}

The main component of Electric Vehicles (VE) is the battery. Lithium-ion batteries have offered the best performance to different technological problems, such as recharge time, autonomy, weight, and energy density. Then, the raised question is what has been their scientific and technological development over time. This paper aims to understand this issue from a bibliometric study and patent analysis of lithium-ion batteries for VE. The results indicate that the dynamics of publication of papers and patent families have been increasing, especially since 2009 , motivated by environmental concerns and the interest of companies in the growth of this market. It highlights the leadership of Asian countries such as Japan, China, South Korea, and Taiwan, as well as the United States and some European countries, in the publication of both papers and patents. Finally, we highlight the collaborative networks between universities for the publication of papers and between incumbent car companies and electric-electronic companies for patenting. These networks demonstrate the need for articulation between different areas of knowledge to advance the technological development of lithium-ion batteries.

KeYwords | Lithium-ion batteries; Electric vehicles; Patent analysis; Bibliometric analysis. 


\section{Introdução}

O combate às mudanças climáticas, a necessidade de redução da emissão de poluentes locais e a pressão por descarbonizar os sistemas de transporte são alguns dos desafios atuais da indústria automobilística mundial. Tais desafios têm imposto uma agenda de Pesquisa e Desenvolvimento (P\&D) de novas tecnologias que buscam ampliar a eficiência energética dos veículos. É em meio a tais exigências que o Veículo Elétrico $(\mathrm{VE})^{1}$ vem ganhando espaço como alternativa para uma mobilidade de baixa-emissão, em oposição aos veículos com Motor a Combustão Interna (MCI), dependentes de combustíveis fósseis.

Os VE não são uma novidade para a indústria automobilística, tendo sua origem há mais de 100 anos. Alguns dos primeiros veículos e trens fabricados em meados do século XIX utilizavam energia elétrica e eram considerados como uma opção limpa e silenciosa para substituir o transporte com cavalos; entretanto, fatores diversos de ordem econômica, tecnológica e social privilegiaram a expansão e domínio dos veículos com $\mathrm{MCI}$, cuja configuração sociotécnica permanece hegemônica (GEELS, 2005).

Depois de décadas de pouca expressão no mercado, é somente a partir dos anos 2000 que os VE começam a acumular volumes de vendas crescentes. No ano de 2019, por exemplo, foram comercializados mais de dois milhóes de unidades de VE, considerando apenas as versôes a bateria e híbrido plug-in, contribuindo com um estoque total em 2019 que supera os sete milhóes de unidades (INTERNATIONAL ENERGY AGENCY - IEA, 2020). São números que podem parecer insignificantes se comparados com o gigantismo das vendas de veículos com MCI, acima de 90 milhôes de unidades anuais (OICA, 2018). Entretanto, em uma perspectiva histórica, em 2005 o estoque global de VE chegava a quase duas mil unidades, mais precisamente 1.890 veículos (IEA, 2019). Tal tendência de crescimento tem se mostrado rápida e contínua ao longo do tempo, reflexo direto dos avanços tecnológicos incorporados nos VE. Neste contexto, ganha destaque o desenvolvimento das baterias, que trazem diferentes composiçóes químicas e capacidade de produção em grande escala (IEA, 2019).

1 Define-se VE como aquele cuja propulsăo de pelo menos uma de suas rodas ocorre por meio de um motor elétrico. Há quatro principais versōes: $100 \%$ movido a bateria; VE híbridos plug-in, que combinam uma bateria e um MCI e permitem flexibilidade no abastecimento; veículos híbridos convencionais que, embora também combinem uma bateria e um MCI, náo permitem o abastecimento com a rede elétrica; e os veículos a hidrogênio, equipados com motor elétrico e sistema de energia baseado em célula a combustível, alimentada por hidrogênio. 
As baterias têm um papel chave no contexto da mobilidade elétrica por serem o elemento mais importante e de maior custo na cadeia de valor dos VE. Diferentemente do veículo com MCI, que depende dos combustíveis fósseis ou dos biocombustíveis para obter sua energia, nos VE a bateria ocupa este papel central. Considerando a relevância das baterias para o impulso da mobilidade elétrica e a necessidade de entender como tem ocorrido este desenvolvimento tecnológico ao longo do tempo, este artigo explora a dinâmica de publicação de artigos científicos e do depósito de patentes para as baterias de lítio-íon e suas aplicações em VE.

Ainda que se tenha no mercado diversos tipos de químicas que alimentam as baterias tais como NiMH (Níquel-hidreto metálico), Zebra (Zeolite Battery Research Africa Project $)^{2}$ e versóes avançadas das tradicionais baterias $\mathrm{PbA}$ de chumbo-ácido como PbA-EFB (Enhaced Floodes Battery) ${ }^{3}$ e PbA-VRLA (Valve Regulated Lead Acid Batteries) ${ }^{4}$, são as baterias de lítio-íon as que estão obtendo melhor aceitação e uma liderança importante no contexto da eletromobilidade (IEA, 2019). Ademais, apresentam maior densidade energética, maior nível de potência e menos peso em comparação com as baterias chumbo-ácido e níquel-cadmio.

As baterias lítio-íon foram introduzidas pela primeira vez na década de 1990 com aplicaçóes diversas, com destaque para equipamentos eletrônicos como telefonia celular, computadores e reprodutores de música (KASSATLY, 2010) para, na sequência, serem absorvidas para aplicação nos VE (IEA, 2018).

Entre as baterias lítio-íon, é possível identificar diversas categorias e aplicaçóes pois os ânodos (polo negativo) e cátodos (polo positivo) podem conter diferentes materiais e composiçóes químicas (CASTRO; BARROS; VEIGA, 2013). Cada uma das combinaçóes possíveis está associada a distintas vantagens e desvantagens em termos de segurança, rendimento, desempenho, custo e outros parâmetros. Os principais tipos de baterias lítio-íon para os cátodos abrangem: Óxido de lítio-cobalto (LCO); Lítio-manganês spinel (LMO); Fosfato de ferro-lítio (LFP), Lítio-níquel-manganês-cobalto (NMC); Lítio-níquel-cobalto-alumínio (NCA). No caso dos ânodos, o principal material é o grafite (IEA, 2018).

Independentemente dos vários tipos, melhorar o custo por kilowatt-hora das baterias lítio-íon continua sendo o principal desafio para a implementação em grande escala dos VE. As baterias de forma geral respondem por cerca de um

2 Também chamadas de baterias de sódio ou sal fundido, porque utilizam este último como eletrólito.

3 Bateria convencional melhorada que permite o uso de uma funçáo start-stop básica.

4 Baterias de chumbo-ácido reguladas por válvula, também chamadas de baterias VRLA. 
terço do custo total de um VE, razão pela qual a diminuição dos seus preços e o aumento da sua escala de fabricação são fatores chave para sua adoção em grande escala (RANDALL, 2016).

São inúmeras as previsóes, elaboradas por instituiçôes e empresas de consultoria, que estimam a queda dos custos das baterias (GOLDIE-SCOT, 2019; IEA, 2013, 2017, 2019; MCKINSEY, 2017). Por exemplo, a International Energy Agency (IEA, 2013) previa que em 2020 o custo da bateria seria de US $\$ 300$ por $\mathrm{kWh}$, prognóstico otimista para a época haja vista que em 2010 os custos das baterias lítio-íon para VE estavam entre 1.160 e 1.000 US $\$ / \mathrm{kWh}$. As empresas automobilísticas também têm anunciado quedas importantes nos custos das baterias: tanto a General Motors como a Tesla Motors afirmaram que alcançarão o custo de US $\$ 100$ por $\mathrm{kWh}$ ainda em 2022 (IEA, 2017; TESLA, 2014). Também o U.S DOE aponta para US\$120 por kWh já em 2022 (IEA, 2017).

Por sua vez, o Relatório Bloomberg NEF (GOLDIE-SCOT, 2019) identificou que o custo real da bateria lítio-íon ${ }^{5}$ já diminuiu $85 \%$ em média, passando de US\$1.160 em 2010 para US\$176 por kWh em 2018. Mantido este ritmo, espera-se que o custo da bateria chegue a US $\$ 62 \mathrm{kWh}$ em 2030 , com uma taxa de aprendizado de $18 \%{ }^{6}$. No mais curto prazo, previsōes diversas convergem ao indicar que ainda em 2022 o custo da bateria poderá ser de US\$100 kWh.

Esta redução pode permitir a paridade dos preços entre um veículo com MCI e um VE em segmentos similares, rompendo esta que é uma das principais barreiras para avançar no mercado de consumo em escala, impulsionando a mudança de paradigma na indústria automobilística (MCKINSEY, 2017; NYKVIST; NILSSON, 2015). A Figura 1 traz projeções da redução dos custos das baterias lítio-íon.

A queda contínua dos custos das baterias lítio-íon tem relação direta com vários elementos: melhoria da química da bateria, especificamente dos cátodos, que permite reduzir a quantidade de materiais de alto custo como o cobalto; novos desenhos da célula da bateria para alcançar uma maior densidade energética; melhoras nos processos de montagem dos pacotes das baterias; e economias de escala na produção (LUTSEY; NICHOLAS, 2019). Outros desenvolvimentos tecnológicos, tais como a adaptaçấo do tamanho da bateria segundo as necessidades de viagem, e o rede-

5 O custo total da bateria lítio-íon corresponde ao pacote completo da bateria, ou seja, a sua célula e os seus custos de integração. A produçấo das células de baterias representa aproximadamente 70\% do custo total da bateria lítio-íon (BOSTON CONSULTING GROUP - BCG, 2018).

6 A taxa de aprendizado é a reduçăo dos custos após uma duplicação cumulativa da produçăo (NYKVIST; NILSSON, 2015). Isto significa que, quando se duplica a produçâo das baterias lítio-íon, observa-se uma redução de $18 \%$ no seu preço. 
senho das plantas de fabricação para uma arquitetura mais simples, aproveitando que os VE têm menos peças que um veículo com MCI, também contribuem com a redução dos custos totais (IEA, 2019).

\section{FIGURA 1}

Custos estimados das baterias lítio-íon para veículos elétricos

(2020-2022-2030)

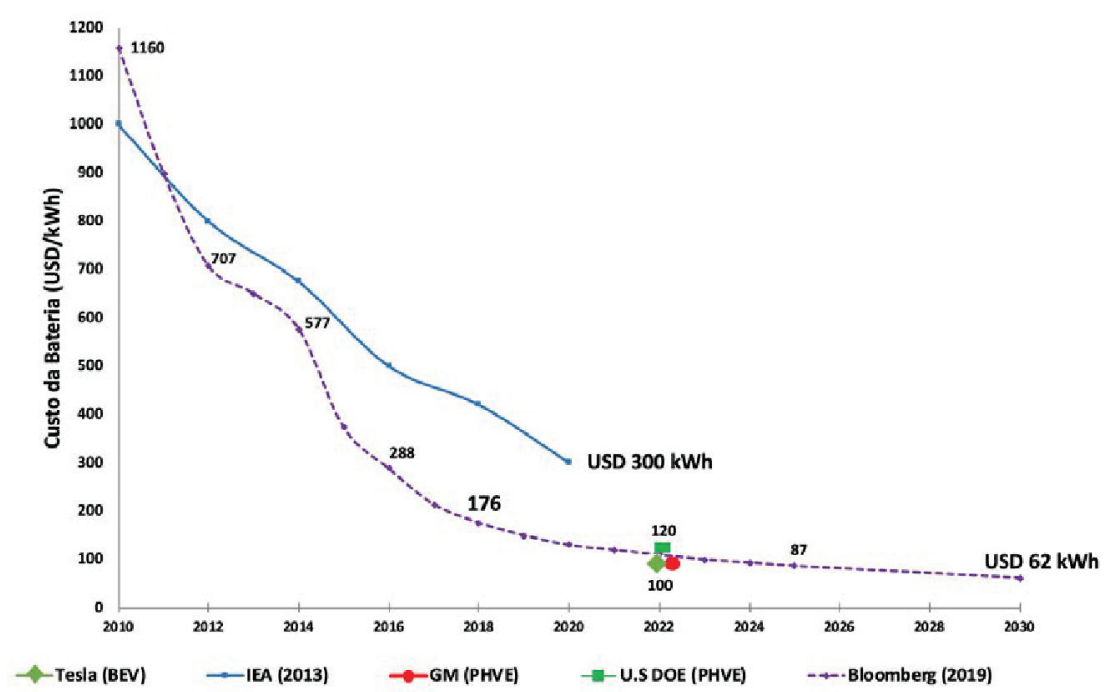

Fonte: Elaboraçăo própria a partir de GOLDIE-SCOT, 2019; IEA, 2013, 2017; MCKINSEY, 2017.

Neste contexto, prevalece alta concorrência entre empresas que buscam melhorar as características tecnológicas da química das baterias (UNITED NATIONS ENVIRONMENT PROGRAMME - UNEP; FRANKFURT SCHOOL, 2016). Somam-se a isso diversos anúncios apontando para a construção de novas fábricas de baterias com foco em lítio-íon ${ }^{7}$, que reforçam a aposta nesta tecnologia. Segundo Bloomberg NEF (GOLDIE-SCOT, 2019), a capacidade de fabricação de baterias triplicou nos últimos cinco anos, apontando para 302,2 gigawatt-hora (GWh) em 2018. A expectativa é que, com a abertura de novas fábricas, até 2025 esta capacidade se amplie para 1 TWh (Terawatt-hora). Estas açóes indicam que as baterias lítio-íon estão configurando-se como o "desenho dominante" para os VE, dada a importância da aprendizagem, da exploração das economias de escala e da redução

7 Empresas da indústria automobilística, como a BYD e do setor eletroeletrônico como Panasonic, LG Chem, CATL, SK Innovation, Samsung SDI, LIBCOIN/BHEL, Northvolt, Lithium Werks e Terra E, anunciaram a instalação de novas plantas de produção de baterias de lítio-íon até 2023, as quais terão uma capacidade de produçẫo de mais de 180 (GWh) por ano (IEA, 2019). 
da incerteza sobre seu desempenho, o que permite fazer investimentos de longo prazo nesta tecnologia (TEECE, 1986).

Dado este comportamento, pode-se dizer que o processo de desenvolvimento tecnológico das baterias lítio-íon para VE situa-se numa segunda etapa do ciclo de vida da tecnologia que, segundo conceito explorado por Utterback; Abernathy (1975), implicaria processos de produção mais eficientes e que caminham para consolidar-se como o desenho ou tecnologia dominante haja vista o nível de maturidade já alcançado. Não obstante, ainda há espaço para inovaçóes de caráter incremental, especificamente nas diferentes composiçóes químicas das baterias, na melhora da densidade energética e na produção em grande escala.

A redução dos custos de produção e comercialização das baterias, por impactar diretamente no custo dos VE, acaba se colocando como sinalizador de crescimento deste mercado na medida em que ocorra maior paridade de preço na comparação com os veículos com MCI. Sendo as baterias de lítio-íon um componente estratégico para a eletromobilidade, as questốes que demandam respostas são: Como tem sido o desenvolvimento tecnológico e científico destas baterias ao longo do tempo? Quais atores estão na liderança destes processos? Há cooperação e compartilhamento de conhecimentos? Por meio de análises bibliométricas e de patentes, este artigo busca trazer respostas a tais questóes.

\section{Cienciometria, bibliometria e patentes como indicadores de inovação e gestão tecnológica}

A cienciometria, assim como a bibliometria, nascem como ferramentas que analisam os resultados das pesquisas publicadas em artigos científicos. A diferença entre elas é de abrangência, uma vez que a cienciometria dedica-se à análise quantitativa da atividade científica e tecnológica, incluindo artigos científicos, documentos técnicos e patentes, razão pela qual se sobrepóe à bibliometria. Segundo Solla Price (1976), precursor da cienciometria, os indicadores cienciométricos podem ajudar a medir a contribuição que cada país dá ao acervo mundial de pesquisa, além de localizar geograficamente as pesquisas por autor, as temáticas abordadas, e acompanhar o crescimento em cada área da ciência. Estas medidas quantitativas são chaves para o estudo dos indicadores científicos e tecnológicos.

Por sua vez, a bibliometria é o estudo dos aspectos quantitativos da produção, disseminação e utilização da informação registrada em artigos científicos que se encontram nas bibliotecas e nas bases de dados. A Bibliometria ajuda a explorar, 
organizar e analisar grandes quantidades de dados, identificando padróes ocultos que podem ajudar aos pesquisadores na tomada de decisóes (DAIM et al., 2006).

Já a análise de patentes é considerada como proxy das atividades inventivas e da dinâmica da inovação. Nos anos 1950, o trabalho de Jacob Schmookler Invention and Economic Development teve grande importância ao utilizar o cômputo de patentes como indicador da mudança tecnológica em várias indústrias como a ferroviária, de papel, refinaria de petróleo e de construção (SCHMOOKLER, 1966).

Estudos de Barberá-Tomás; Jiménez-Sáez; Castelló-Molina (2011); Ernst (1997); Gao et al. (2013); Jaffe; Trajtenberg (2002); Watanabe; Tsuji; Griffy-Brown (2001), entre outros, indicam que as patentes servem para identificar padróes de mudança técnica em sistemas tecnológicos complexos e para analisar a evolução das diferentes trajetórias tecnológicas ao longo de um período de tempo. A vantagem é que documentos de patentes representam um dos principais insumos de informação da inovação, pois dizem respeito a invenções com certa probabilidade de virem a ter participação no mercado e se configurarem como inovaçóes. Além disso, os documentos de patentes são importantes como fonte de informação tecnológica dado que têm uma estrutura normalizada, classificação internacional, incluem todos os setores da tecnologia e são de fácil acesso on-line a partir dos diferentes escritórios de patentes, nacionais e regionais.

É importante salientar os limites acerca das patentes, quando estas se apresentam como indicadores de atividades de inovação. Por exemplo, há casos em que a opção por proteção das invençóes ocorre por meio de segredos industriais, e não de patentes. Também há casos de patentes sem valor econômico e que só são registradas para desviar a atenção dos concorrentes sobre o verdadeiro foco das pesquisas. Além disso, algumas patentes podem ser consideradas de "baixa qualidade" por terem poucas possibilidades de se transformarem em inovaçóes. Também é importante considerar que embora as patentes devam cumprir determinados requisitos para que lhes seja outorgada a proteção, os níveis de rigor podem ser distintos, dependendo dos critérios adotados pelos escritórios de patentes dos países. Não obstante estas críticas, a análise, tanto de artigos como de patentes, representa uma importante fonte de informação científica e tecnológica e mostra-se central para o estudo de tendências e dinâmicas da inovação em países, indústrias e organizações. 


\section{Metodologia}

Os resultados deste artigo se apoiam em monitoramento tecnológico, também conhecido como vigilância tecnológica. Trata-se de um processo sistemático que captura, analisa e divulga informação de origens diversas (econômica, tecnológica, política, social, cultural, legislativa) por meio de métodos legais, com o objetivo de identificar e antecipar oportunidades e riscos, para melhorar a formulação e implementação da estratégia nas organizações (SÁNCHEZ; PALOP, 2002).

Para tanto, o processo de vigilância tecnológica exige a busca exaustiva em fontes primárias e secundárias, com a interação junto a especialistas e atores chaves com conhecimento sobre a temática de estudo. Neste artigo, o exercício de vigilância tecnológica foi desenvolvido em quatro fases:

Fase 1. Definiçáo de temas e objetivos: compreendeu a priorização das tecnologias de baterias lítio-íon de VE e a definição das palavras-chave para a construção das equaçôes de busca. Isso se deu a partir da revisão preliminar de fontes secundárias e da consulta a um grupo de especialistas, que ajudaram a guiar o processo, interpretar a informação e refinar a pesquisa. O período de análise definido tanto para os artigos como para as patentes foi de 1996 até 2016.

A equação de busca (conforme Apêndice 1) para identificar os artigos científicos combinou as diferentes composiçôes químicas das baterias lítio-íon com palavras relacionadas à mobilidade elétrica; estas palavras-chave foram definidas a partir de revisão bibliográfica prévia. A busca de patentes combinou tais palavras-chave com os Códigos Internacionais de Patentes (CIP) das baterias lítio-íon para VE, identificados por Faria e Andersen (2015) e complementada com uma revisão exaustiva dos principais CIP relacionados com acumuladores de lítio. Termos como bicicletas, barcos, telefones, aviōes, entre outros, foram excluídos da equação de busca. Tanto a equação dos artigos científicos como a das patentes, contaram com a posterior validação de especialistas em baterias para veículos elétricos vinculados à Fundação $\mathrm{CPqD}$ (Centro de Pesquisa e Desenvolvimento em Telecomunicaçóes).

Fase 2. Busca e coleta de informaçáo: para a busca dos artigos científicos, foi utilizada a base de dados Scopus ${ }^{8}$; para patentes, o Questel-Orbit, sistema de busca de "famílias de patentes", ou seja, busca por grupos de invençôes que, tal como uma família, estão relacionados entre si por meio da data de prioridade. Isto significa que a mesma invenção é protegida em escritórios de patentes de países

8 A Base de dados Scopus apresentou um número maior de resultados na comparaçáo com a base Web of Science (WOS). 
diferentes, mas conservando a data de prioridade do primeiro depósito ${ }^{9}$. $\mathrm{O}$ uso de famílias de patentes tem como vantagem a melhor comparabilidade internacional, além de evitar a duplicidade de resultados (ORGANISATION FOR ECONOMIC CO-OPERATION AND DEVELOPMENT - OECD, 2009).

Fase 3. Processamento da informação: foi utilizado o software de mineração de dados Vantage Point. Nesta fase, foi feita uma limpeza dos dados e o agrupamento entre palavras-chave e instituiçóes que apareciam com nomes distintos.

Fase 4. Análise da informação: os tópicos, foco de investigação, compreenderam:

- Dinâmica de publicação de artigos científicos e de patenteamento (considerando a data de prioridade da família de patente), entre 1996-2016;

- Países líderes em publicação de artigos científicos e prioridade dos depósitos de patentes;

- Instituiçóes líderes que publicam artigos e depositam famílias de patentes. Para o caso das patentes, as instituiçóes foram classificadas em: i) montadoras e empresas de autopeças; ii) empresas do setor eletroeletrônico; e iii) empresas de energia elétrica, institutos de P\&D e universidades;

- Redes de colaboração entre instituiçóes;

- Áreas de conhecimento e principais temáticas.

\section{Principais resultados}

\subsection{Dinâmica de publicação de artigos científicos e famílias de patentes}

Para o período 1996-2016 foram identificadas $\mathbf{1 5 . 3 7 5}$ famílias de patentes e $\mathbf{5 . 5 3 5}$ artigos científicos relacionados com o tema das baterias lítio-íon para VE, conforme Figura 2.

Observa-se que principalmente a partir de 2005 a dinâmica de patenteamento e de publicação de artigos científicos em torno das baterias de lítio-íon para veículos elétricos assume nova configuração, apresentando um incremento constante com centenas de novos textos publicados por ano. No caso das patentes, nota-se um crescimento em ritmo bastante acentuado entre 2009 e 2011, ano em que alcança seu pico, seguido de uma interrupção no ritmo de crescimento (2012 a 2014), e

9 A data de prioridade é de grande importância jurídica, já que com ela se outorga o direito de prioridade e se delimita o estado da técnica. Esta data define o ano em que se registrou a patente, que é a data mais relacionada com a data da invenção (OECD, 2009). 
novamente aumento nos registros indicando que esta queda não implica um desinteresse na temática. Interessante observar que o período pós anos 2010 coincide com a ampliação do mercado de consumo de VE que toma ritmo a partir de entáo e se mantém em crescimento acentuado e constante, conforme apresentado nas estatísticas da IEA (2019).

FIGURA 2

Dinâmica de publicaçáo de artigos científicos e famílias de patentes de baterias lítio-íon para VE (1996-2016)

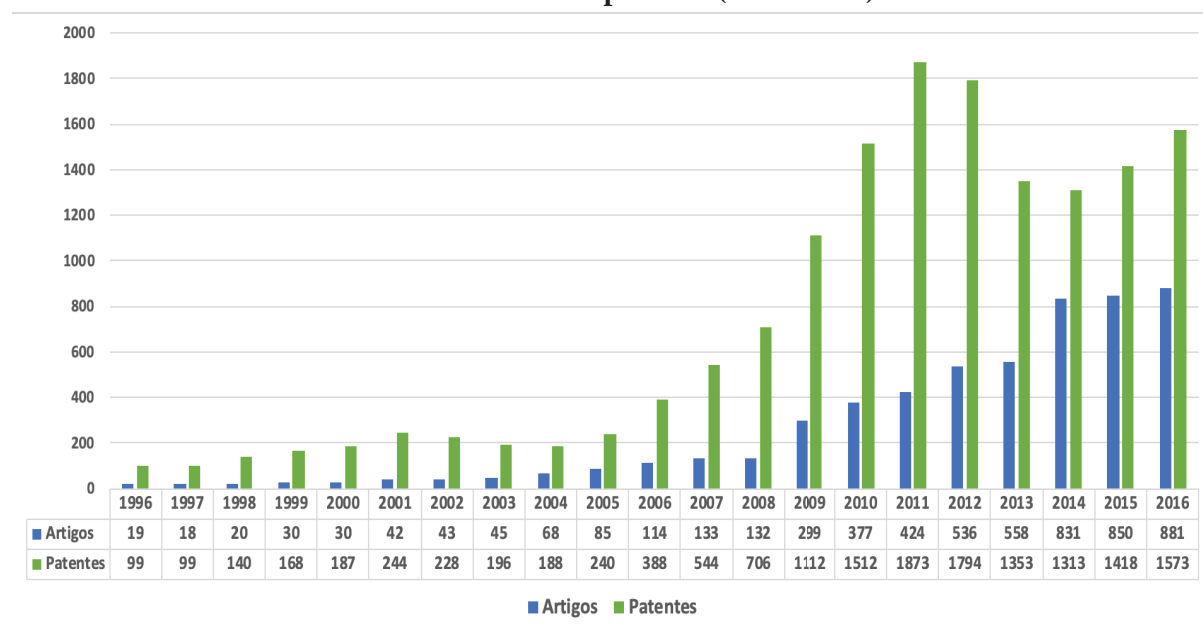

Fonte: Elaboração própria a partir do Scopus e Questel-Orbit, processamento em Vantage Point.

O aumento das atividades inventivas e de pesquisa na segunda década dos anos 2000 também tem sido impulsionado por questôes ambientais, em especial devido às pressóes regulatórias associadas às mudanças climáticas e a qualidade do ar. Deve ser considerado o fato de terem sido criados programas de P\&D para o desenvolvimento de VE e baterias em vários países (CONSONI et al., 2018). Além disso, o desenvolvimento de baterias para a eletrônica de consumo tem sido importante para a aplicação desta tecnologia no setor de transporte, especificamente para os VE (DIJK; ORSATO; KEMP, 2013; GOLEMBIEWSKI et al., 2015).

\subsection{Países líderes}

Os países líderes são os locais em que se originou a invenção (país de prioridade) e onde foram publicados os artigos. A identificação dos países líderes permite capturar as diferentes capacidades de $\mathrm{P} \& \mathrm{D}$ e de invenção num campo tecnológico, neste caso 
das baterias lítio-íon para VE (ALBINO et al., 2014). A Tabela 1 traz o número total de famílias de patentes e de artigos publicados por país, com seu ranking e a sua porcentagem de participação no total. Os resultados mostram que os países que estão na liderança dos registros de patentes e de artigos são os mesmos que estáo empreendendo esforços há anos, com políticas diversificadas, para consolidar sua indústria de veículos elétricos.

TABELA 1

Países líderes em publicação de famílias de patentes e artigos científicos de baterias lítio-íon para VE e porcentagem de participaçáo no total (1996-2016)

\begin{tabular}{l|crrrrrr}
\hline \multirow{2}{*}{ País } & \multicolumn{3}{c|}{ Famílias de patentes } & \multicolumn{3}{c}{ Artigos científicos } \\
\cline { 2 - 7 } & Ranking & \multicolumn{1}{c}{ Total } & \multicolumn{1}{c}{ \% } & Ranking & \multicolumn{1}{c}{ Total } & \multicolumn{1}{c}{$\%$} \\
\hline Japão & $(1)$ & 5216 & 33,9 & $(4)$ & 386 & 7,0 \\
China & $(2)$ & 2682 & 17,4 & $(1)$ & 1359 & 24,5 \\
Estados Unidos & $(3)$ & 1355 & 8,8 & $(2)$ & 1359 & 24,5 \\
Alemanha & $(4)$ & 1166 & 7,6 & $(3)$ & 404 & 7,3 \\
Coreia do Sul & $(5)$ & 1102 & 7,2 & $(5)$ & 332 & 6,0 \\
França & $(6)$ & 280 & 1,8 & $(7)$ & 212 & 3,8 \\
Taiwan & $(7)$ & 91 & 0,6 & $(10)$ & 141 & 2,5 \\
Reino Unido & $(8)$ & 47 & 0,3 & $(6)$ & 218 & 3,9 \\
Canadá & $(9)$ & 33 & 0,2 & $(9)$ & 203 & 3,7 \\
Tailândia & $(10)$ & 23 & 0,1 & $(32)$ & 19 & 0,3 \\
Itália & $(12)$ & 18 & 0,1 & $(8)$ & 208 & 3,8 \\
Brasil & $(24)$ & 3 & 0,02 & $(33)$ & 14 & 0,2 \\
Outros & & 3.359 & 21,8 & & 680 & 13,0 \\
Total & & & $\mathbf{1 0 0 , 0}$ & & 5.535 & & $\mathbf{1 0 0 , 0}$ \\
\hline
\end{tabular}

Fonte: Elaboraçấo própria a partir do Questel-Orbit e Scopus, processamento em Vantage Point.

Tanto para o caso das patentes, como dos artigos, é importante salientar a liderança de países asiáticos como Japão, China, Coreia do Sul e Taiwan, com mais de $58 \%$ das patentes e mais de $40 \%$ de todos os artigos científicos arbitrados sobre baterias lítio-íon. Desde o início da década de 1990, os governos destes países apoiaram a indústria de baterias com subsídios e investimentos, para que pudessem ocupar parcelas deste mercado. Estes países também se caracterizam por terem uma forte tradição em empresas do setor eletroeletrônico, para as quais as baterias lítio-íon são um nicho de mercado importante. 
O Japão, que ocupa o primeiro lugar em patenteamento, tinha desde 1992 programas de P\&D específicos para o desenvolvimento de baterias lítio-íon, com fortes investimentos do governo japonês. Alguns dos programas mais destacados são: New Sunshine Programme (1992); Advanced Clean Energy (1997-2003); Next Generation Vehicle Strategy (2010) e mais recentemente o Excellent Advanced Batteries Development Project (2009-2015), que tinha como objetivo desenvolver baterias de nova geração (CONSONI et al., 2018).

No caso da China, tem destaque o Projeto de Pesquisa 863 que começou em 2001 no marco do Plano Nacional de Desenvolvimento 10th National Five-Year Plan (2001-2005). O Projeto 863 destinou uma grande quantidade de recursos para ampliar a capacidade científica e tecnológica da China em VE. Por exemplo, o 12th National Five-Year Plan (2011-2015) estabeleceu que de 2011 até 2020 o governo investiria pelo menos US\$ 18 bilhóes para estimular a indústria de VE, dos quais US\$ 26 milhôes foram destinados exclusivamente para o desenvolvimento de baterias lítio-íon (CONSONI et al., 2018).

Os Estados Unidos também têm destaque, ocupando o segundo lugar em artigos científicos $(24,5 \%)$ e o terceiro $(8,8 \%)$ em patentes. O governo estadunidense tem destinado recursos para incentivo à $\mathrm{P} \& \mathrm{D}$ em laboratórios nacionais e em universidades com reflexos já percebidos a partir do número de patentes com foco nesta tecnologia. Durante o governo de Barack Obama (de 2009 a 2017), a indústria de baterias lítio-íon foi considerada estratégica para estimular a economia, diminuir a dependência do petróleo e impulsionar o desenvolvimento de uma indústria automobilística mais limpa e competitiva. Esta priorização implicou investimentos em mais de US $\$ 2$ bilhôes de subvençôes para estimular o desenvolvimento e fabricação nacional de materiais e componentes para baterias lítio-íon para VE. Este projeto foi coordenado pelo Departamento de Energia dos Estados Unidos (U.S DOE) e financiado com recursos do American Recovery and Reinvestment Act.

Também têm merecido destaque as patentes depositadas em países europeus como Alemanha, França, Reino Unido e Itália, detentores de uma indústria automobilística bem desenvolvida.

O Brasil, ainda que se coloque em posição inferior em publicação de artigos científicos e patentes, apresentou 14 artigos científicos vinculados às universidades e centros de P\&D, com destaque para Universidade Tecnológica Federal do Paraná, Universidade Estadual de Campinas, Universidade Federal de Santa Maria e do $\mathrm{CPqD}$ de Campinas. O país também participa com três famílias de patentes com 
depósitos via Tratado de Cooperação de Patentes (PCT) liderado por empresas estrangeiras como Volvo e Nissan.

\subsection{Instituições líderes}

Em relação às instituições líderes, como já era de se esperar, as universidades e centros de pesquisa se sobressaem na publicação de artigos científicos, enquanto as empresas são maioria entre os depositantes de patentes. O exercício a seguir mostra quem são estas instituiçôes.

$\mathrm{Na}$ Figura 3 consta o número de artigos publicados pelas instituiçôes líderes e a sua relação com os principais países. Esta figura evidencia que os artigos são publicados conjuntamente por pesquisadores de instituições de diferentes países e confirma a liderança da China, Estados Unidos e Alemanha nas pesquisas sobre baterias de lítio-íon para VE.

FIGURA 3

Instituiçóes e países líderes em publicação de artigos científicos de baterias lítio-íon para VE (1996-2016)

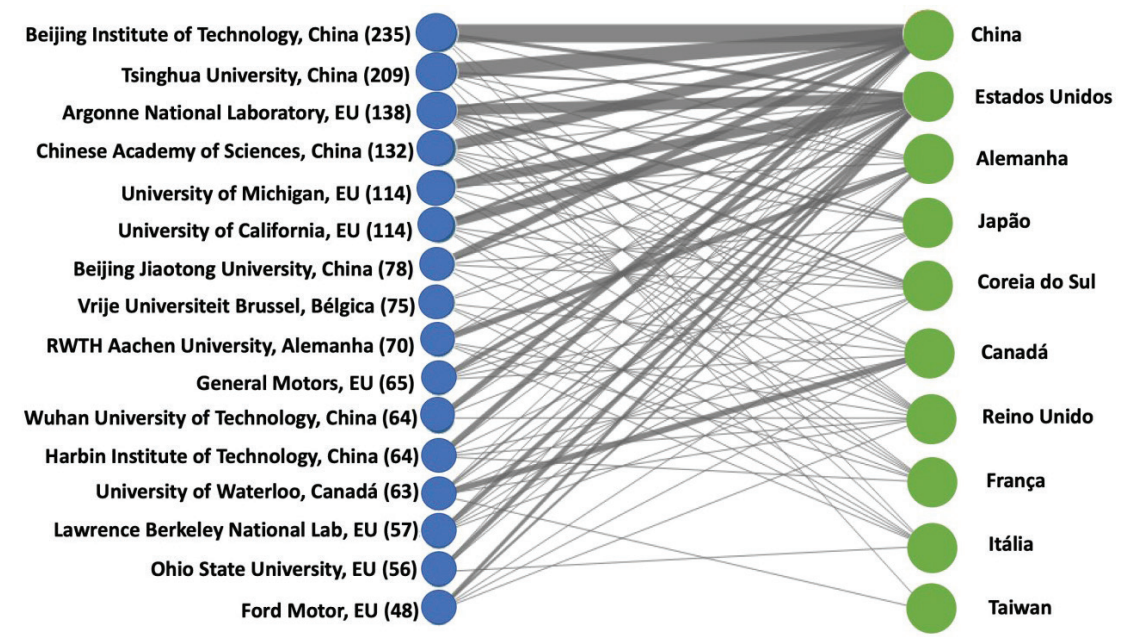

Fonte: Elaboraçăo própria a partir do Scopus, processamento em Vantage Point.

A liderança nas publicaçóes é ocupada por seis universidades chinesas: Beijing University of Technology; Tsinghua University; Chinese Academy of Sciences; Beijing Jiaotong University; Wuhan University of Technology; e Harbin Institute of 
Technology. Além disso, há outras universidades e montadoras que publicam em conjunto com universidades chinesas.

No caso dos Estados Unidos, cinco instituiçôes se destacam: Argonne National Laboratory e Lawrence Berkeley National Laboratory, que trabalham com mobilidade elétrica, baterias de VE e energias alternativas; University of Michigan, University of California e Ohio State University, que têm centros de pesquisa relacionados com tecnologias de transporte elétrico e da indústria automobilística. Aqui vale pontuar a participação de duas montadoras, a General Motors (65 artigos) e a Ford Motor (48 artigos). A General Motors apresenta resultados das pesquisas do General Motors Research and Development Center, GM Chemical Sciences and Materials Systems Lab, GM Global Vehicle Engineering em parceria com diferentes universidades, principalmente dos Estados Unidos. No caso da Ford, os artigos são publicados pelos diferentes centros de P\&D da montadora como: Ford Research and Innovation Center, Ford Sustainability Mobility Technologies e Ford Research and Advanced Engineering, entre outros.

Há duas universidades europeias: Vrije Universiteit Brusel da Bélgica, que tem o centro de pesquisa Mobi (Mobility, Logistics and Automotive Technology Research Center) em temas sobre mobilidade elétrica e políticas para o transporte sustentável; e a alemã RWTH Aachen (Rheinisch-Westfalische Technische Hochschule Aachen), com 30 institutos de pesquisa de diferentes áreas do conhecimento na área de mobilidade elétrica e sua integração com os sistemas de tráfego.

Também é importante a participação da University of Waterloo do Canadá, com vários grupos de pesquisa e laboratórios focados no desenvolvimento de baterias lítio-íon para VE e para outras aplicaçôes. Dois grupos de pesquisa destacados são: Applied Nanomaterials \& Clean Energy Laboratory e The Nazar Group, do Departamento de Química e da Engenharia Química.

Em relação às patentes, foram selecionadas as 60 instituições com maior número de depósitos, organizadas em três categorias e dispostas nas Tabelas 2, 3 e 4: i) montadoras e empresas de autopeças, com participação de 43,3\%; ii) empresas do setor elétrico e eletrônico (43,3\%); e iii) Empresas de Energia Elétrica, Universidades e Centros de P\&D (13,3\%).

A Tabela 2, sobre montadoras e empresas de autopeças, indica a forte presença de empresas incumbentes que, embora ainda centralizadas na tecnologia do MCI, estấo contribuindo com a produção de conhecimentos sobre mobilidade elétrica. 
TABELA 2

Montadoras e empresas de autopeças líderes em patenteamento das baterias lítio-íon para VE (1996-2016)

\begin{tabular}{|c|c|c|c|}
\hline $\begin{array}{c}\text { Montadora/Empresa de } \\
\text { autopeças }\end{array}$ & $\begin{array}{l}\text { № de famílias } \\
\text { de patentes }\end{array}$ & $\begin{array}{c}\text { Montadora/Empresa de } \\
\text { autopeças }\end{array}$ & $\begin{array}{l}\text { Node famílias } \\
\text { de patentes }\end{array}$ \\
\hline 1. Toyota Motor (Japão) & 1.480 & 14. BYD (China) & 59 \\
\hline 2. Robert Bosch (Alemanha) & 522 & 15. Audi (Alemanha) & 58 \\
\hline 3. Nissan Motor (Japão) & 366 & $\begin{array}{l}\text { 16. Kia Motors (Coreia do } \\
\text { Sul) }\end{array}$ & 53 \\
\hline 4. Denso (Japão) & 308 & 17. Subaru (Japão) & 53 \\
\hline 5. Honda Motor (Japão) & 290 & 18. Yazaki (Japão) & 50 \\
\hline $\begin{array}{l}\text { 6. Hyundai Motor (Coreia } \\
\text { do Sul) }\end{array}$ & 173 & $\begin{array}{l}\text { 19. Chery Automobile } \\
\text { (China) }\end{array}$ & 48 \\
\hline 7. Daimler (Alemanha) & 152 & 20. Yamaha Motor (Japão) & 48 \\
\hline 8. General Motors (EU) & 151 & 21. Suzuki Motor (Japão) & 47 \\
\hline 9. Ford Motor (EU) & 143 & 22. Porsche (Alemanha) & 36 \\
\hline $\begin{array}{l}\text { 10. Mitsubishi Motors } \\
\text { (Japão) }\end{array}$ & 109 & 23. Volkswagen (Alemanha) & 32 \\
\hline 11. Renault (França) & 95 & 24. Mazda Motor (Japão) & 31 \\
\hline 12. BMW (Alemanha) & 69 & $\begin{array}{l}\text { 25. Continental Automotive } \\
\text { (Alemanha) }\end{array}$ & 29 \\
\hline 13. Peugeot-Citroën (França) & 60 & 26. Tesla Motors (EU) & 28 \\
\hline
\end{tabular}

Fonte: Elaboraçáo própria a partir do Questel-Orbit, processamento em Vantage Point.

Destacam-se empresas montadoras japonesas como Toyota Motor, Nissan Motor, Honda Motor, Mitsubishi Motors, Subaru, Yazaky, Yamaha Motor, Suzuki Motor e Mazda Motor com modelos de veículos elétricos e híbridos e joint-ventures com empresas do setor elétrico e eletrônico para o desenvolvimento de baterias lítio-íon. Dentre as autopeças, aparece a empresa Denso, que desenvolve componentes para as baterias para VE como conversores DC-DC, sensores de corrente, sistemas de monitoramento para baterias, inversores entre outros.

Montadoras norte-americanas, como as centenárias General Motors e Ford Motor, além da nova entrante no setor, a Tesla Motors, a qual já nasceu como uma empresa dedicada ao desenvolvimento e comercialização de VE, aparecem com destaque no número de famílias de patentes.

Dentre as alemãs, também são destaque as montadoras tradicionais Daimler, BMW, Audi, Porsche, Volkswagen e as autopeças Robert Bosch e Continental Automotive. A Bosch, por exemplo, adquiriu a start up norte-americana Seeo Inc., 
especializada em tecnologias para células de baterias no estado sólido, que permite melhorar a densidade energética das baterias, na busca por reduzir os custos das baterias para VE (BOSCH, 2016).

$\mathrm{Na}$ França, Renault e Peugeot-Citroën aparecem no ranking das patentes de baterias para veículos elétricos e híbridos.

Por fim, é importante salientar a atuação de empresas asiáticas como as coreanas Kia Motors e Hyundai, e das chinesas BYD (Build Your Dreams) e Chery Automobile, fundadas, respectivamente, em 1997 e 2012. As montadoras chinesas, além de contarem com forte apoio do Estado chinês em relação à coordenação de políticas industriais e apoio à P\&D (CONSONI et al., 2018), foram largamente contempladas com a transferência tecnológica a partir das montadoras tradicionais, fato fundamental para a formação de capacidades tecnológicas em processos produtivos e no desenvolvimento de novas tecnologias (TEIXEIRA, 2015). Particularmente, a BYD tem sido reconhecida por seu posicionamento no segmento dos carros, ônibus e caminhóes elétricos, e no desenvolvimento de baterias de lítio ferro-fosfato. Pode-se dizer que a eletromobilidade tem sido uma oportunidade para que montadoras chinesas estabeleçam uma posição mais equitativa frente a seus concorrentes mundiais, os quais têm a liderança na produção de veículos com MCI (TEECE, 2018).

Neste cenário da mobilidade elétrica, são inúmeras as empresas do ramo da eletrônica e sistemas elétricos que desenvolvem baterias para VE, principalmente baterias lítio-íon, sistemas de gestâo de baterias (BMS) e outros componentes associados às baterias, como conectores para o carregamento. Isto evidencia que a participação destes novos entrantes é chave para o desenvolvimento de tecnologias disruptivas, porque podem importar uma tecnologia de uma indústria para outra (CHRISTENSEN, 1997). Além disso, estudos de Golembiewski et al. (2015); Mueller; Sandner e Welpe, (2015) destacam que empresas externas à indústria automobilística inovam fortemente nas tecnologias de baterias para VE e têm se posicionado como parceiras estratégicas para a indústria automobilística.

A Tabela 3 traz as empresas do setor eletroeletrônico com patentes relacionadas com baterias de lítio-íon para VE.

Novamente, ganham destaque empresas asiáticas, principalmente da Coreia do Sul como LG Chem e Samsung SDI. LG Chem é fornecedora de baterias para os modelos GM Volt e Renault Zoe e também é fornecedora de BMS (Battery Management System), um componente chave nas baterias. Por sua vez, a Samsung 
SDI utilizou as capacidades e conhecimentos adquiridos na elaboração de baterias de celulares para o desenvolvimento de baterias lítio-íon para VE e híbridos.

TABELA 3

Empresas do setor eletroeletrônico líderes em patenteamento das baterias lítio-íon para veículos elétricos (1996-2016)

\begin{tabular}{|c|c|c|c|}
\hline $\begin{array}{l}\text { Empresas Setor } \\
\text { Eletroeletrônico }\end{array}$ & $\begin{array}{c}\text { №-de famílias } \\
\text { de patentes }\end{array}$ & $\begin{array}{c}\text { Empresas setor elétrico- } \\
\text { eletrônico }\end{array}$ & $\begin{array}{c}\text { №-de famílias } \\
\text { de patentes }\end{array}$ \\
\hline 1. LG Chem (Coreia do Sul) & 622 & 14. General Electric (EU) & 55 \\
\hline $\begin{array}{l}\text { 2. Samsung SDI (Coreia do } \\
\text { Sul) }\end{array}$ & 339 & 15. NEC (Japão) & 56 \\
\hline 3. Hitachi (Japão) & 307 & 16. Johnson Controls (EU) & 54 \\
\hline 4. Panasonic (Japão) & 303 & 17. Siemens (Alemanha) & 47 \\
\hline 5. Sony (Japão) & 271 & 18. GS Yuasa (Japão) & 45 \\
\hline 6. Sanyo Electric (Japão) & 240 & 19. CPS Technology (EU) & 38 \\
\hline $\begin{array}{l}\text { 7. Murata Manufacturing } \\
\text { (Japão) }\end{array}$ & 217 & 20. IHI (Japão) & 35 \\
\hline 8. Mitsubishi Electric (Japão) & 175 & 21. Sharp (Japão) & 35 \\
\hline 9. Toshiba (Japão) & 141 & $\begin{array}{l}\text { 22. Zhejiang Chaowei } \\
\text { Chuangyuan Ind. (China) }\end{array}$ & 32 \\
\hline $\begin{array}{l}\text { 10. Sumitomo Corporation } \\
\text { (Japão) }\end{array}$ & 139 & $\begin{array}{l}\text { 23. Chugoku Electric Power } \\
\text { (Japão) }\end{array}$ & 26 \\
\hline 11. SB Limotive (Coreia do Sul) & 104 & $\begin{array}{l}\text { 24. LS Industrial Systems } \\
\text { (Coreia do Sul) }\end{array}$ & 26 \\
\hline 12. NGK Insulators (Japão) & 61 & $\begin{array}{l}\text { 25. Li-Tec Battery } \\
\text { (Alemanha) }\end{array}$ & 25 \\
\hline 13. Nitto Kogyo (Japão) & 59 & $\begin{array}{l}\text { 26. Primearth EV Energy } \\
\text { (Japão) }\end{array}$ & 25 \\
\hline
\end{tabular}

Fonte: Elaboraçăo própria a partir do Questel-Orbit, processamento em Vantage Point.

De fato, tanto a LG Chem como a Samsung SDI são apontadas pela Navigant Research (2015) como líderes no mercado de baterias lítio-íon para VE e de produtos de eletrônicos de consumo. Estas empresas têm alcançado uma produção em larga escala, o que tem permitido reduzir seus custos de produção com células de lítio-íon de alta qualidade. Outra empresa coreana com destaque é SB Limotive, uma joint-venture entre Bosch e Samsung SDI, porém dissolvida em 2012.

Empresas tradicionais japonesas no ramo da eletrônica, tais como Hitachi, Panasonic, Sony, Sanyo Electric, Murata, Mitsubishi Electric, Toshiba, Sumitomo Corporation, NGK, NEC, entre outras, também aparecem no ranking. O avanço 
da mobilidade elétrica fez com que os interesses destas empresas convergissem para o desenvolvimento de baterias lítio-íon.

O exemplo ilustrativo refere-se ao acordo selado entre Panasonic e Tesla Motors para a construção da Gigafactory em Nevada, Estados Unidos, para produção das baterias lítio-íon em maior volume (35 GWh ao ano; em 2018, tinham alcançado $20 \mathrm{GWh}$ ) e com custo menor ( $30 \%$ menos que seu modelo anterior). A construção teve início em 2014 e está sendo conduzida em fases permitindo que a fábrica opere nas seçôes já finalizadas e continue a se expandir.

Com relação às empresas norte-americanas, a General Electric desenvolve e comercializa estaçóes de carregamento para VE e está trabalhando em aliança com o Berkeley National Laboratory para o desenvolvimento de uma bateria de fluxo (flow battery) que utiliza combinaçóes baseadas em soluçóes aquosas de produtos inorgânicos, as quais fornecem uma alta densidade energética para os veículos elétricos (GENERAL ELECTRIC GLOBAL RESEARCH, 2016).

Por sua vez, a Johnson Controls, também uma empresa tradicional voltada à fabricação e comercialização de baterias chumbo-ácido, tem participação no registro de patentes de baterias lítio-íon como um nicho de mercado importante.

Finalmente, é interessante observar na Tabela 4 o comportamento de empresas do setor de energia elétrica, de universidades e de centros de P\&D entre as instituições líderes em patenteamento. Salienta-se a participação expressiva do caso chinês, com a liderança da empresa estatal State Grid Corporation of China (SGCC) e de cinco universidades, dedicadas ao desenvolvimento de equipamentos de distribuiçấo e transmissão de energia elétrica, smart grid e projetos de pesquisa em redes de carregamento para veículos elétricos.

A SGCC iniciou em 2006 projetos de pesquisa em VE; em 2011, esta instituição detinha uma frota de 350 veículos elétricos, tendo prestado serviços para mais de 450.000 veículos externos (híbridos e elétricos). Também construiu a operação de estaçóes de carregamento e mantém projetos de demonstração na província de Zhejiang. A SGCC propôs o modelo de negócio BCCU "Battery Swapping as Main Service, Charging as Supplement, Centralized Recharging and Unified Distribution", que tinha como objetivo melhorar os sistemas de carregamento para VE, reduzir o impacto nas redes de distribuição de energia e centralizar a gestáo de riscos associados ao desenvolvimento da indústria dos veículos elétricos (LI; GE; ZHAN, 2012). 
TABELA 4

Empresas de energia elétrica, universidades e centros de P\&D líderes no patentamento de baterias lítio-íon para VE (1996-2016)

\begin{tabular}{l|c}
\hline \multicolumn{1}{c|}{ Empresas de energia elétrica, universidades e centros de P\&D } & $\begin{array}{c}\text { № de famílias } \\
\text { de patentes }\end{array}$ \\
\hline 1. State Grid Corporation of China (SGCC) (China) & 54 \\
2. South China University of Technology (China) & 36 \\
3. Beijing University of Technology (China) & 31 \\
4. CEA - Commissariat A L Energie Atomique Et Aux Energies & 30 \\
Alternatives (França) & \\
5. China Electric Power Research Institute (CEPRI) (China) & 29 \\
6. Tsinghua University (China) & 26 \\
7. Korea Institute of Science and Technology (Coreia do Sul) & 24 \\
8. Harbin University of Science and Technology (China) & 21 \\
\hline
\end{tabular}

Fonte: Elaboração própria a partir do Questel-Orbit, processamento em Vantage Point.

Dentre as universidades chinesas, a South China University of Technology tem vários centros de P\&D e laboratórios como a School of Environment and Energy e o Key Laboratory of Advanced Energy Storage Materials, que desenvolvem pesquisas relacionadas com baterias lítio-íon, baterias de sodio-íon, smart grids e suas aplicaçóes na mobilidade elétrica (SOUTH CHINA UNIVERSITY OF TECHNOLOGY, 2018).

A Tsinghua University tem projetos de pesquisa nos Departamentos de Engenharia Química e Engenharia Elétrica relacionados com VE e baterias lítio-íon e mantém parcerias com a Alemanha por meio da Sino-German Network on Electromobility para analisar testes de desempenho, novos componentes para baterias de VE e o ciclo de vida das baterias lítio-íon (SINO-GERMAN NETWORK ON ELECTROMOBILITY, 2016).

Finalmente, vale mencionar o Centro de P\&D da França CEA (Commissariat à l'energie atomique et aux énergies alternatives) que, juntamente com o centro de P\&D Liten Institute, trabalham no desenvolvimento de baterias de lítio-íon em toda a cadeia de valor, desde a fabricação das células até a montagem do pacote da bateria. Além de pesquisas em baterias de litio-ferro-fosfato, lítio-sulfuro e do estado de carga das baterias e ônibus elétricos, este centro também desenvolve projetos em colaboração com empresas como Renault e Michelin (COMMISSARIAT À L'ÉNERGIE ATOMIQUE ET AUX ÉNERGIES ALTERNATIVES - CEA, 2018). 


\subsection{Redes de colaboração}

Por se tratar de uma tecnologia ainda em fase de consolidaçấo e que incorpora conhecimento que dialoga com diversas áreas tais como engenharias, eletroeletrônica e química, as parcerias e atividades de cooperaçáo acabam sendo um ativo importante para a geração de novo conhecimento em torno das baterias lítio-íon.

Há pelo menos 30 anos, no Modelo de Competências Dinâmicas, Teece (1986) desenvolveu o argumento que a capacidade de integração entre o conhecimento externo e interno é importante para o sucesso da firma via desenvolvimento colaborativo ou redes. As redes de colaboraçáo entre empresas de diferentes setores produtivos refletem a necessidade de se conduzir atividades de P\&D conjuntamente, em uma perspectiva de complementaridade de conhecimentos e expertises, objetivando alcançar maior competitividade. Estas colaboraçôes são um meio de compartilhamento de conhecimentos e riscos acerca da P\&D, como também uma forma de avançar no desenvolvimento das tecnologias de baterias e agregar valor em toda a cadeia produtiva (GOLEMBIEWSKI et al., 2015). Estas redes de colaboração também permitem o acesso a tecnologias complementares e a outros ativos necessários para competir na medida que a indústria evolui (TEECE, 2018).

No exercício aqui apresentado, sobre baterias lítio-íon para VE, a observação das redes de colaboração permite visualizar as diferentes colaboraçôes adotadas por universidades, centros de pesquisa, setores automotivo, eletroeletrônico e de energia para o desenvolvimento da base científica e tecnológica das baterias.

No que concerne à publicação de artigos científicos, as redes de colaboração apontam para a importância da publicação conjunta entre universidades e laboratórios de $\mathrm{P} \& \mathrm{D}$ e, em menor proporção, das montadoras ${ }^{10}$. Destacam-se as publicaçôes conjuntas entre universidades chinesas lideradas pela Beijing Institute of Technology, a qual também mantém artigos com universidades estadunidenses. Outros destaques abarcam as redes de colaboração entre Universidades e Laboratórios de P\&D dos Estados Unidos, em parcerias com montadoras tradicionais como a General Motors e a Ford Motor (Figura 4).

O protagonismo das empresas tradicionais novamente se faz presente. As redes de colaboração para o depósito de patentes estão sendo lideradas por montadoras como Toyota, Hyundai e empresas do setor eletroeletrônico como Panasonic, conforme Figura 5. Nota-se que os grandes players do setor têm buscado se posicionar neste novo mercado tecnológico emergente, estabelecendo parcerias tanto entre si, como alianças com empresas do setor eletroeletrônico.

10 Para a construçấo das redes de colaboraçấo, foram selecionadas as instituiçôes com maior número de artigos publicados no período de análise. 
FIGURA 4

Redes de colaboraçáo para a publicaçáo de artigos científicos de baterias lítio-íon para VE (1996-2016)

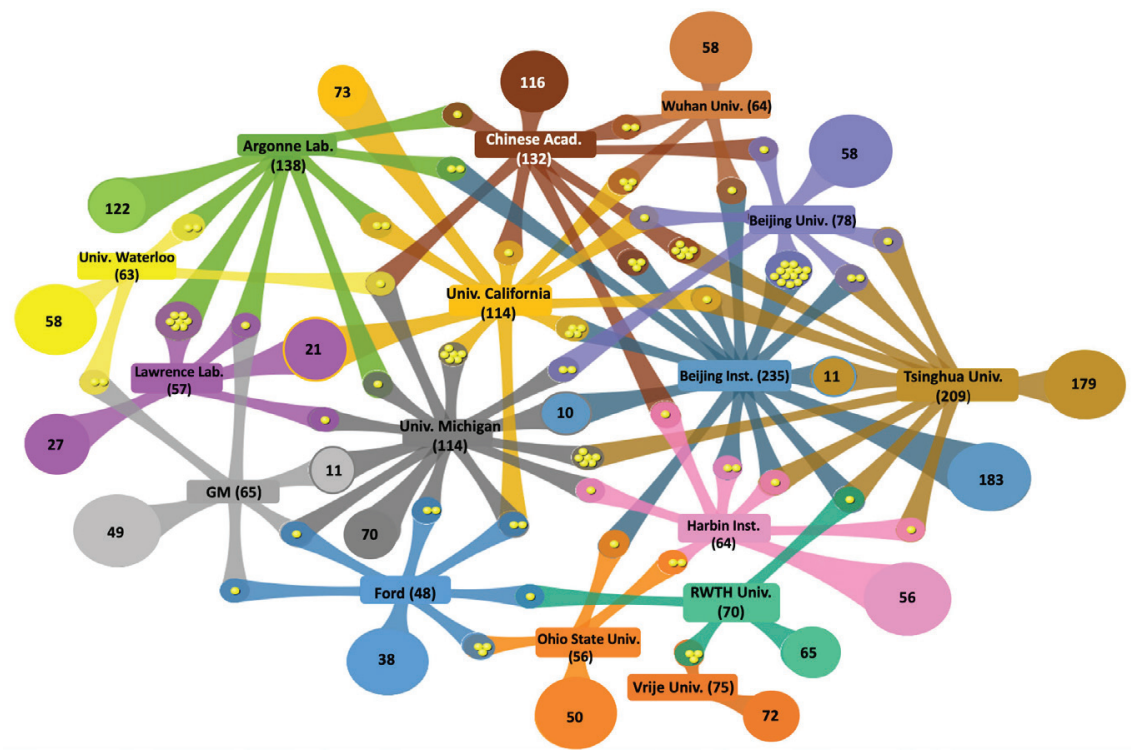

Fonte: Elaboração própria a partir do Scopus, processamento em Vantage Point.

FIGURA 5

Redes de colaboraçáo entre empresas líderes em patenteamento de baterias lítio-íon para VE (1996-2016)

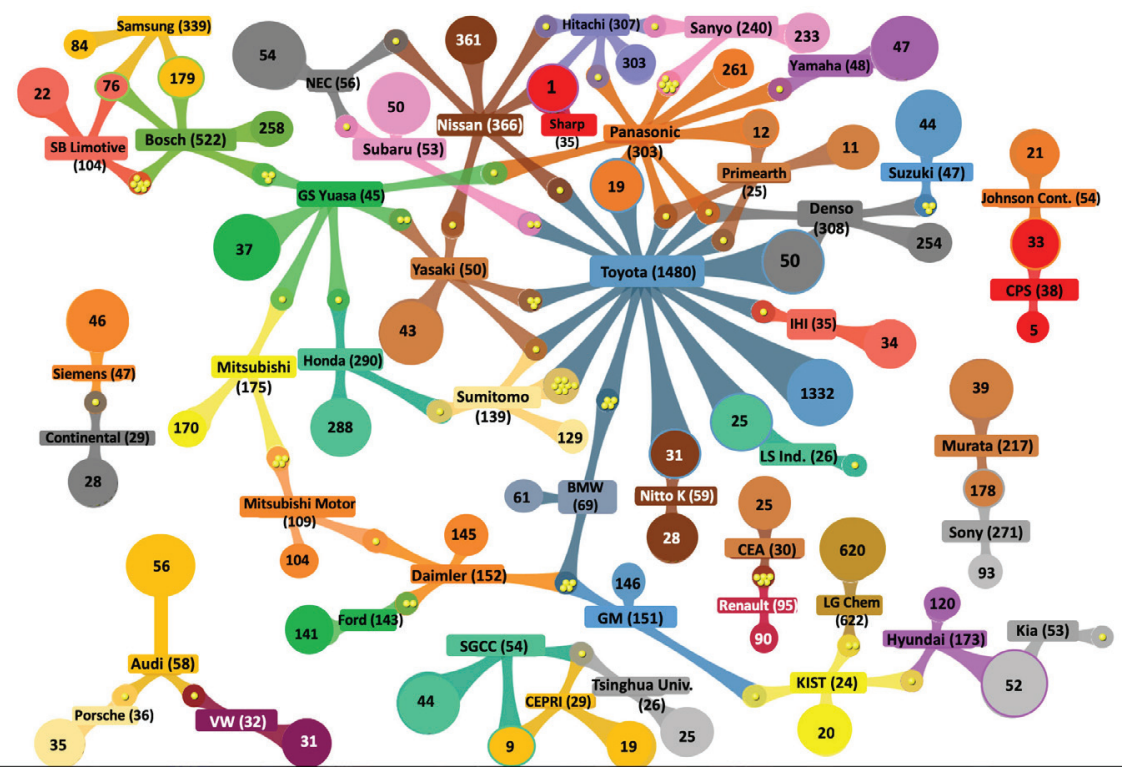

Fonte: Elaboraçáo própria a partir do Questel-Orbit, processamento em Vantage Point. 
Sobre a intensidade das ligaçóes de cooperação, o caso das empresas japonesas merece maior atenção pois além de deterem um número importante de patentes, estas empresas também contratam atividades de $\mathrm{P} \& \mathrm{D}$ junto a empresas tradicionais do setor eletroeletrônico. Este movimento sinaliza para a implementação de um modelo de inovação aberta, em que é possível aproveitar a propriedade intelectual interna e externa, licenciando patentes ou desenvolvendo patentes em conjunto para o benefício do próprio modelo de negócio (CHESBROUGH, 2003; GOLEMBIEWSKI et al., 2015). Por exemplo, a Toyota, empresa na liderança em patentes de baterias lítio-íon, também tem patentes com empresas de autopeças, como a Denso e a Yazaki, e do setor eletrônico como Panasonic, Fujitsu Ten e Sumitomo. O mesmo ocorre com a rede formada pela japonesa Nissan, com patentes em conjunto com empresas do setor eletrônico (Hitachi, Sharp e NEC) em prol ao desenvolvimento de baterias lítio-íon dos modelos Nissan Leaf e para os modelos derivados da aliança Renault-Nissan (Renault Twizy e Renault Kangoo).

Nesta mesma linha, vale destacar a rede formada pela montadora norte-americana General Motors, com patentes em conjunto com as alemãs BMW e Daimler. Ainda que estas empresas sejam grandes líderes de produção de veículos MCI, também apresentam modelos de VE tais como o Chevrolet Volt e as várias versôes elétricas da BMW. No caso da Daimler, em 2019 a empresa anunciou que está interrompendo os projetos de motores a combustáo interna, para se dedicar à eletrificação e às baterias mais eficientes (LAMBERT, 2019).

No contexto de centralização e coordenação da indústria de VE na China, a State Grid Corporation of China (SGCC) tem patentes em conjunto com sua subsidiária China Electric Power Research Institute (CEPRI) e com a Tsinghua University, com trabalhos colaborativos em temáticas relacionadas com energias renováveis, novos materiais, vehicle to grid (V2G) e sistemas de carregamento para veículos elétricos.

Há ainda outras redes de colaboração que se destacam, porém com número menor de instituiçôes. Uma delas é formada pelas empresas coreanas Hyundai, Kia e o Centro de Pesquisa Korea Institute of Science and Technology (KIST). Assim como verificado na China, também na Coreia do Sul prevalece uma forte relaçáo entre empresas nacionais para o desenvolvimento de setores estratégicos.

No caso francês, as colaboraçóes entre Renault e o Centro de P\&D CEA são resultado do Programa Cash for Clunkers, o qual ofereceu um pacote de ajuda financeira às montadoras para superar a crise econômica de 2009. Como parte deste Programa, o governo federal francês contribuiu com 125 milhôes de euros para a 
construção de uma fábrica de baterias de lítio-íon da aliança Renault-Nissan em parceria com a CEA. O montante total do projeto foi de 625 milhóes de euros (IEA, 2010; CONSONI et al., 2018).

No caso alemão, empresas pertencentes ao mesmo grupo empresarial, Volkswagen, Porsche e Audi, desenvolveram uma nova arquitetura para as baterias de VE denominada "flat battery packs", confeccionadas em alumínio, com maior capacidade para armazenar energia, alcançando autonomia de mais de 300 quilômetros. Outra rede envolve colaboração entre Samsung SDI e Bosch por meio da joint-venture SB Limotive que tinha como alvo o desenvolvimento de baterias lítio-íon para veículos elétricos. SB Limotive teve duração de quatro anos e, embora dissolvida em 2012, as empresas mantêm acesso gratuito às patentes desenvolvidas no período da aliança (BOSCH, 2012).

Apesar das várias parcerias identificadas, há também empresas que são líderes no depósito de patentes e que preferem desenvolver suas invençóes internamente e sem cooperação. É o caso de empresas com representatividade no setor, tais como Toshiba, NGK Insulators, Peugeot-Citroën, BYD, General Electric, Chery Automobile, Mazda e Tesla, entre outras.

\section{5 Áreas do conhecimento e principais temáticas}

Por fim, cabem algumas informaçóes sobre as tecnologias para as baterias lítio-íon para VE, as quais têm sido construídas a partir da interface entre os setores automotivo, químico e eletroeletrônico. Tem sido necessária a experiência nestas três disciplinas, além dos conhecimentos das empresas de baterias, para o desenvolvimento de pesquisas com uma abordagem colaborativa. Esta integração é um elemento crucial para a adoção dos VE e evidencia-se nas redes de colaboração, licenciamento e patentes conjuntas (GOLEMBIEWSKI et al., 2015).

Esta integração de conhecimentos também fica evidente nas temáticas abordadas nos artigos científicos, nos quais há a predominância de áreas como engenharia (41,1\%), energia (19,1\%), química (10,8\%) e ciências dos materiais $(6,8 \%)$. Também se destacam áreas como ciências da computação (6,4\%), ciências do meio ambiente (5,3\%), física e astronomia (3,3\%), matemáticas (3,2\%) e ciências sociais $(1,4 \%)$.

As áreas do conhecimento das famílias de patentes não se diferem do que ocorre com os artigos científicos, com destaque para: maquinaria elétrica e energia; transporte; medição; controle; motores, bombas, turbinas; materiais, metalurgia, entre outros (Figura 6). Assim como no caso dos artigos científicos, é interessante a 
integração entre áreas de conhecimento "não tradicionais" da indústria automobilística como as Tecnologias da Informação e Comunicação, tecnologias da computação, tecnologias do meio ambiente e comunicação digital, entre outras.

FIGURA 6

Áreas de conhecimento das patentes das baterias lítio-íon para VE (1996-2016)

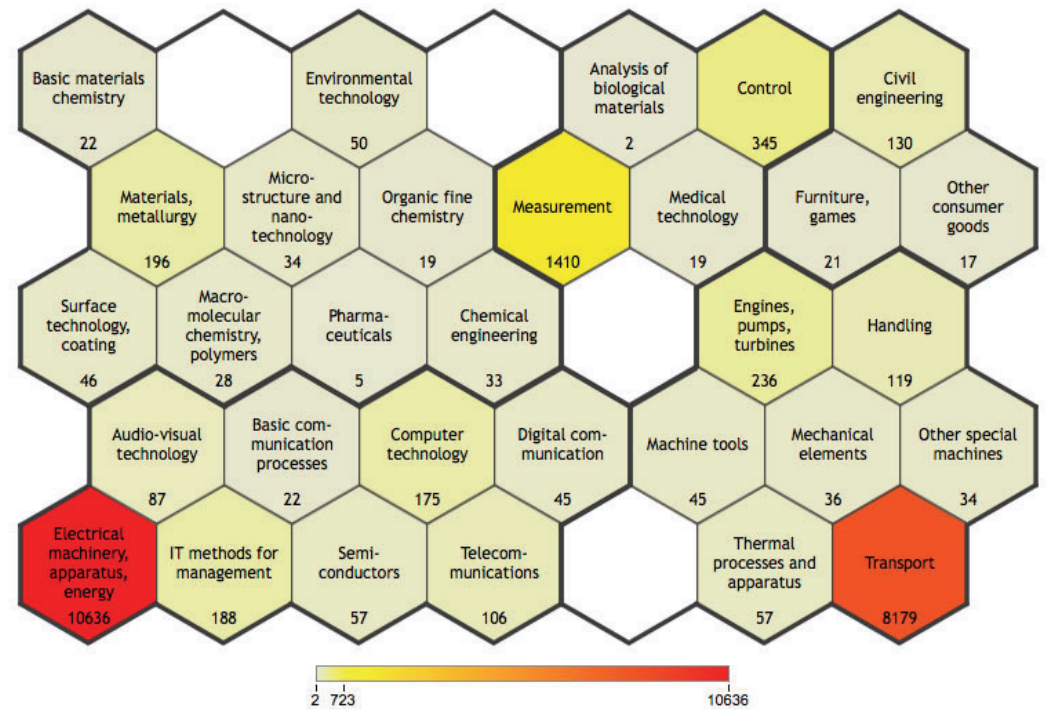

Fonte: Elaboração própria a partir do Questel-Orbit.

Outro dos aspectos analisados nos artigos científicos foram as palavras-chave relativas às baterias lítio-íon e seus componentes tais como lítio, iones, elétrodos, cátodos, ânodos e eletrólitos. As temáticas mais presentes nos artigos científicos, identificadas a partir das palavras-chave, dizem respeito aos principais problemas das baterias lítio-íon para VE, por exemplo: sistema de carga e descarga de baterias, baterias secundárias, estado de carga (State of Charge SOC) e temperatura. Também são importantes os Battery Management System (BMS), assim como as estimações, simulaçóes por computador, optimização e o uso de algoritmos, como componentes complementares para melhorar a eficiência e a gestâo das baterias lítio-íon para VE. Outras palavras-chave identificadas estáo associadas a tecnologias alternativas às baterias para VE, por exemplo: células de combustível, capacitores e baterias chumbo-ácido.

No caso das patentes, predominam conceitos relacionados com sistemas de carregamento das baterias, carregamento de $\mathrm{VE}$, recarga rápida, montagem de bateria, dispositivos de armazenamento de energia e baterias lítio-íon. 


\section{Considerações finais}

A contribuição deste artigo consistiu em identificar a dinâmica da produção científica e das trajetórias tecnológicas das baterias lítio-íon para VE, o envolvimento e liderança dos autores e instituiçóes (universidades, centros de P\&D, montadoras, e empresas do setor de energia e elétrico e eletrônico) e mapear as redes de colaboração entre elas.

A bateria é a tecnologia mais crítica de um VE; apesar das várias opçóes tecnológicas e químicas disponíveis, as baterias de lítio-íon têm apresentado maior densidade energética, maior nível de potência, menor peso e menor impacto ao meio ambiente. Entretanto, ainda há espaço para inovaçôes de caráter incremental, especificamente nas diferentes composiçôes químicas das baterias, na melhora da densidade energética e na produção em grande escala. Desafios como melhorar o desempenho e o custo por kilowatt-hora das baterias são certamente fatores impulsionadores do crescimento de mercado da eletromobilidade. E este tem sido um esforço continuado que se manifesta a partir da dinâmica crescente da publicação de artigos científicos e do registro de famílias de patentes sobre as baterias lítio-íon, contribuindo para ampliar o arcabouço de conhecimentos nesta área. Algumas tendências merecem destaque.

Nota-se que países que são líderes na publicação de artigos científicos sobre baterias íon-lítio também lideram os registros de depósitos de patentes. É o caso dos países asiáticos como Japão, China, Coreia do Sul e Taiwan, dos Estados Unidos e, em menor proporção, dos países europeus como Alemanha e França.

Sobre os atores por trás destas dinâmicas, tem-se o protagonismo das universidades e dos laboratórios de $\mathrm{P} \& \mathrm{D}$ com maior propensão à publicaçấo de artigos científicos na comparaçâo com as empresas. Neste aspecto, a liderança das universidades chinesas é bastante evidente. Vale pontuar que duas montadoras, ambas dos Estados Unidos, aparecem entre as principais instituiçôes que publicam artigos científicos.

Sobre os líderes em depósito de patentes tem-se, de um lado, montadoras e fabricantes de autopeças com 43,3\% dos registros; de outro, as empresas do setor eletroeletrônico, com igual percentual (43,3\%); o restante dos registros pertencem às universidades, institutos de pesquisa e empresas de energia. Qualificando melhor quem são estes líderes em depósitos de patentes, aparece o protagonismo das empresas tradicionais, em todos os setores mencionados, um sinalizador de que o mercado das baterias para VE está longe de ser uma exclusividade dos novos entrantes ou mesmo da indústria automobilística. Em paralelo, há participação importante de novas 
entrantes (newcomers) do setor automotivo, como as montadoras chinesas BYD e Chery Automobile e a estadunidense Tesla, esta última com origem no Silicon Valley.

Outro importante aspecto que merece atenção é a existência de redes de colaboração entre empresas e instituições de um mesmo país, e entre países, o que sinaliza a existência de incentivos públicos e privados e programas de $P \& D$ para o desenvolvimento de capacidades tecnológicas na mobilidade elétrica e em seus diferentes componentes. Além disso, a diversidade de áreas do conhecimento e de disciplinas que aparecem nos registros de patentes e nas publicaçóes científicas sobre baterias lítio-íon explicam a necessária interface que tem ocorrido entre os setores automotivo, químico e eletroeletrônico, com a consequente abordagem colaborativa.

Estas parcerias, aliás, vão além do aspecto da "geração de conhecimento" e estão envolvendo empreendimentos físicos, como é o caso da construção de diferentes fábricas de baterias de lítio-íon ao redor do mundo, como a Gigafactory da Tesla em aliança com a japonesa Panasonic. A colaboração entre montadoras e fabricantes de baterias lítio-íon permitirá promover adequaçóes rapidamente nos processos de produção, ajustados às novas dimensóes e químicas das células e integrar novos desenhos nos VE (BCG, 2018).

Por fim, no contexto do desenvolvimento científico e tecnológico das baterias de lítio-íon, é essencial considerar o papel estratégico dos governos. Por um lado, é importante a formação de mão de obra especializada, a promoção de atividades de P\&D e de projetos de demonstração que tenham como alvo melhorar a química das baterias, aumentar a densidade energética, a segurança e diminuir seu impacto ambiental. Por outro lado, também é importante o estímulo às capacidades de produção de baterias lítio-íon em grande escala, dado o caráter estratégico deste novo mercado. Para tanto, o estímulo à proteção da propriedade intelectual e às redes de colaboração entre o setor automobilístico, empresas de autopeças, empresas de baterias, universidades, laboratórios e centros de $\mathrm{P} \& \mathrm{D}$, passa a ser ativo significativo e tende a contribuir com a redução dos custos de produção das baterias em direção a um mercado de massa, e não mais de nicho.

Neste sentido, é importante que novas pesquisas analisem o papel das políticas públicas de estímulo à $\mathrm{P} \& \mathrm{D}$ e das capacidades locais de produção, a fim de avaliar sua efetividade na promoção de tecnologias relacionadas com as baterias de lítio-íon para VE. 


\section{Agradecimentos}

Agradecemos aos pareceristas encarregados pela revisão deste artigo e a todos os pesquisadores do Laboratório de Estudos do Veículo Elétrico (Leve), do Departamento de Política Científica e Tecnológica do Instituto de Geociências da Universidade Estadual de Campinas, pela constante interação e discussão sobre o tema da eletromobilidade.

\section{Referências}

ALBINO, V.; ARDITO, L.; DANGELICO, R.; PETRUZZELLI, A. Understanding the development trends of low-carbon energy technologies: A patent analysis. Applied Energy, v. $135,2014$.

BARBERÁ-TOMÁS, D.; JIMÉNEZ-SÁEZ, F.; CASTELLÓ-MOLINA, I. Mapping the importance of the real world: The validity of connectivity analysis of patent citations networks. Research Policy, v. 40, n. 3, p. 473-486, 2011.

BOSCH. Bosch expands development and production of efficient storage technology, 13 Dec. 2012. Disponível em: http://www.bosch-presse.de/pressportal/de/en/bosch-expands-developmentand-production-of-efficient-storage-technology-42035.html. Acesso em: 6 fev. 2018.

BOSH. Bosch has groundbreaking battery technology for electric vehicles, 2016. Disponível em: https://www.bosch-presse.de/pressportal/de/en/bosch-has-groundbreaking-batterytechnology-for-electric-vehicles-43063.html. Acesso em: 5 fev. 2018.

BOSTON CONSULTING GROUP (BCG). The Future of Battery Production for Electric Vehicles. Boston, 2018. Disponível em: https://www.bcg.com/publications/2018/futurebattery-production-electric-vehicles.aspx. Acesso em: 20 jan. 2020.

CASTRO, B.H.R.; BARROS, D.C.; VEIGA, S.G. Baterias automotivas: panorama da indústria no Brasil, as novas tecnologias e como os veículos elétricos podem transformar o mercado global. BNDES Setorial, v. 37, p. 443-496, 2013.

COMMISSARIAT À L'ÉNERGIE ATOMIQUE ET AUX ÉNERGIES ALTERNATIVES (CEA). Lithium-Ion Batteries: Promising Greater Energy Efficiency for Transportation, 2018. Disponível em: http://liten.cea.fr/cea-tech/liten/en/Pages/techno Energy Efficiency/ LiionBatteries.aspx. Acesso em: 20 jan. 2020.

CHESBROUGH, H.W. The Era of Open Innovation. MIT Sloan Management Review, p. 35-42, 15 Apr. 2003.

CHRISTENSEN, C.M. The Innovator's Dilemma: When New Technologies Cause Great Firms to Fail. Boston, MA: Harvard Business School Press, 1997. 
CONSONI, F.L. et al. Estudo de governança e politicas públicas para veículos elétricos. Brasília D.F: Ministério da Indústria, Comercio Exterior e Serviços MDIC, 2018.

DAIM, T.U.; RUEDA, G.; MARTIN, H.; GERDSRI, P. Forecasting emerging technologies: Use of bibliometrics and patent analysis. Technological Forecasting \& Social Change, v. 73, n. 8, p. 981-1012, 2006.

DIJK, M.; ORSATO, R.J.; KEMP, R. The emergence of an electric mobility trajectory. Energy Policy, v. 52, p. 135-145, 2013.

ERNST, H. The Use of Patent Data for Technological Forecasting: The Diffusion of CNCTechnology in the Machine Tool Industry. Small Business Economics, v. 9, n. 4, p. 361-381, 1997.

FARIA, L.; ANDERSEN, M.M. The evolution of green patenting activity in the automotive sector (1965-2012). In: GERPISA INTERNATIONAL COLLOQUIUM, 23., Paris. Anais [...]. Paris: 2015.

GAO, L. et al. Technology life cycle analysis method based on patent documents. Technological Forecasting \& Social Change, v. 80, n. 3, p. 398-407, 2013.

GEELS, F.W. The dynamics of transitions in socio-technical systems: A multi-level analysis of the transition pathway from horse-drawn carriages to automobiles (1860-1930). Technology Analysis and Strategic Management, v. 17, n. 4, p. 445-476, 2005.

GENERAL ELECTRIC GLOBAL RESEARCH. A Recipe for Powering Next-Generation Electric Vehicles. 2016. Disponível em: https://www.geglobalresearch.com/blog/recipepowering-next-generation-electric-vehicles. Acesso em: 6 fev. 2018.

GOLDIE-SCOT, L. A Behind the Scenes Take on Lithium-ion Battery Prices. Bloomberg $N E F$, Blog, 5 Mar. 2019. Disponível em: https://about.bnef.com/blog/behind-scenes-takelithium-ion-battery-prices/. Acesso em: 20 jan. 2020.

GOLEMBIEWSKI, B.; STEIN, N.; SICK, N.; WIEMHÖFER, H.-D. Identifying trends in battery technologies with regard to electric mobility: Evidence from patenting activities along and across the battery value chain. Journal of Cleaner Production, v. 87, n. C, p. 800-810, 2015. INTERNATIONAL ENERGY AGENCY (IEA). Hybrid and Electric Vehicles. The Electric Drive AdvancesAnnual Report. [s.l: s.n.].

INTERNATIONAL ENERGY AGENCY (IEA). Global EV Outlook. Understanding the Electric Vehicle Landscape to 2020, Apr. 2013. Disponível em: https://www.ourenergypolicy. org/wp-content/uploads/2013/09/GlobalEVOutlook_2013.pdf. Acesso em: 7 fev.2018.

INTERNATIONAL ENERGY AGENCY (IEA). Global EV Outlook 2017. Two million and counting, 2017. Disponível em: http://www.oecd-ilibrary.org/energy/global-ev-outlook2017_9789264278882-en. Acesso em: 15 set. 2018. 
INTERNATIONAL ENERGY AGENCY (IEA). Global EV Outlook 2018. Towards crossmodal electrification, 2018. Disponível em: https:/www.oecd-ilibrary.org/energy/global-evoutlook-2018_9789264302365-en. Acesso em: 20 out. 2018.

INTERNATIONAL ENERGY AGENCY (IEA). Global EV Outlook 2019. Scaling-up the transitions to electric mobility, 2019. Disponível em: https:/www.iea.org/publications/ reports/globalevoutlook2019/. Acesso em: 20 jul. 2019.

INTERNATIONAL ENERGY AGENCY (IEA). Global EV Outlook 2020.Entering the decade of electric drive?, 2020. Disponível em: https://www.iea.org/publications/reports/ globalevoutlook2020/. Acesso em: 05 jun. 2019.

INSTITUTO NACIONAL DA PROPRIEDADE INDUSTRIAL (INPI). Estratégia de busca. Importância do uso estratégico da informação tecnológica em bases de patentes. In: ENAPID, 8., Rio de Janeiro. Anais [...]. Rio de Janeiro: 2015. (Mini-curso do Enapid).

JAFFE, A.B.; TRAJTENBERG, M. Patents, citations and innovations: A window on the knowledge economy. Cambrigde; Massachusetts: MIT Press, 2002.

KASSATLY, S. The Lithium-Ion Battery Industry for Electric Vehicles. Thesis (S.M.) Massachusetts Institute of Technology, Dept. of Mechanical Engineering, 2010.

LAMBERT, F. Daimler stops developing internal combustion engines to focus on electric cars. Electrek, 19 Sept. 2019. Disponível em: https://electrek.co/2019/09/19/daimler-stopsdeveloping-internal-combustion-engines-to-focus-on-electric-cars/. Acesso em: 12 fev. 2020.

LI, L.; GE, X.; ZHAN, Y. Development of Electric Vehicles: Opportunities and Challenges for Power Grid Companies. In: 2012 CHINA INTERNATIONAL CONFERENCE ON ELECTRICITY DISTRIBUTION (CICED 2012). Shanghai, 2012, p. 1-7. doi: 10.1109/ CICED.2012.6508460.

LUTSEY, N.; NICHOLAS, M. Update on electric vehicle costs in the United States through 2030. International Council on Clean Transportation (ICCT), 2019. (Working Paper, 2019-06). Disponível em: https://theicct.org/sites/default/files/publications/EV_ cost_2020_2030_20190401.pdf.

MCKINSEY. Electrifying insights: How automakers can drive electrified vehicle sales and profitability. Advanced Industries. New York: McKinsey \& Company, 2017.

MUELLER, S.C.; SANDNER, P.G.; WELPE, I.M. Monitoring innovation in electrochemical energy storage technologies: A patent-based approach. Applied Energy, v. 137(C), p. 537544, 2015. DOI: 10.1016/j.apenergy.2014.06.082.

NAVIGANT RESEARCH. Lithium Ion Batteries for Transportation, 2015. Disponível em: https://www.navigantresearch.com/ research/navigant-research-leaderboard-report-lithiumion-batteries-for-transportation. Acesso em: 17 set. 2018. 
NYKVIST, B.; NILSSON, M. Rapidly falling costs of battery packs for electric vehicles. Nature Climate Change, v. 5, n. 4, p. 329-332, 2015.

ORGANISATION FOR ECONOMIC CO-OPERATION AND DEVELOPMENT (OECD). OECD Patent Statistics Manual. [s.l: s.n.].

OICA. Sales Statistics | OICA. International Organization of Motor Vehicle Manufacturers, 2018. Disponível em: http://www.oica.net/category/sales-statistics/. Acesso em: 11 set. 2018. PRICE, D.J.D.S. Little Science, Big Science ... and Beyond. New York: Columbia University Press, 1976.

RANDALL, T. Here's How Electric Cars Will Cause the Next Oil Crisis. Bloomberg NEF, 25 Feb. 2016. Disponível em: https://www.bloomberg.com/features/2016-ev-oil-crisis/. Acesso em: 5 nov. 2017.

SÁNCHEZ, M.; PALOP, F. Herramientas de software para la práctica en la empresa de la Vigilancia Tecnológica e Inteligencia Competitiva. Evaluación Comparativa. 1. ed. España: TRIZ, 2002.

SCHMOOKLER, J. Invention and economic growth. London: Harvard University Press, 1966. SINO-GERMAN NETWORK ON ELECTROMOBILITY. TU9 Electromobility, 2016. Disponível em: http://www.sinogermanemobility.de/. Acesso em: 6 fev. 2018.

SOUTH CHINA UNIVERSITY OF TECHNOLOGY. Overview of Schools, 2018. Disponível em: http://en.scut.edu.cn/detail.jsp?id=26883. Acesso em: 6 fev. 2018.

TEECE, D.J. Profiting from technological innovation: Implications for integration, collaboration, licensing and public policy. Research Policy, v. 15, p. 285-305, 1986.

TEECE, D.J. Tesla and the Reshaping of the Auto Industry. Management and Organization Review, v. 14, n. 3, p. 501-512, 2018.

TEECE, D.J. China and the reshaping of the auto industry: A dynamic capabilities perspective. Management and Organization Review, v. 15, n.1, p. 177- 199, 2019.

TEIXEIRA, R.D. O Estado e as empresas multinacionais no desenvolvimento produtivo e tecnológico da indústria automobilística chinesa. 2015. Dissertação (Mestrado em Política Científica e Tecnológica) - Instituto de Geociências, Universidade Estadual de Campinas Unicamp, Campinas, 2015.

TESLA. Panasonic and Tesla Sign Agreement for the Gigafactory, 30 July 2014. Disponível em: https://www.tesla.com/blog/panasonic-and-tesla-sign-agreement-gigafactory. Acesso em: 6 fev. 2018. 
UNITED NATIONS ENVIRONMENT PROGRAMME (UNEP); FRANKFURT SCHOOL. Global Trends in Renewable Energy Investment 2016. Frankfurt, 2016. Disponível em: https:/www.actu-environnement.com/media/pdf/news-26477-rapport-pnue-enr.pdf. Acesso em: 25 set. 2018.

UTTERBACK, J. M.; ABERnATHY, W. J. A Dynamic Model of Process and Product Innovation. OMEGA, v. 3, n. 6, p. 639-65, 1975.

WATANABE, C.; TSUJI, Y.S.; GRIFFY-BROWN, C. Patent statistics: Deciphering a "real" versus a "pseudo" proxy of innovation. Technovation, v. 21, n. 12, p. 783-790, 2001.

\section{Contribuição das autoras:}

A. Fundamentação teórico-conceitual e problematização: Tatiana BermúdezRodríguez e Flávia Luciane Consoni

B. Pesquisa de dados: Tatiana Bermúdez-Rodríguez e análise estatística:Tatiana Bermúdez-Rodríguez e Flávia Luciane Consoni

C. Elaboração de figuras e tabelas: Tatiana Bermúdez-Rodríguez

D. Elaboração e redação do texto: Tatiana Bermúdez-Rodríguez e Flávia Luciane Consoni

E. Seleção das referências bibliográficas: Tatiana Bermúdez-Rodríguez e Flávia Luciane Consoni

Conflito de Interesse: as autoras declaram que não há conflito de interesses.

Fonte de financiamento: Este artigo é resultado de um Projeto de Pesquisa e Desenvolvimento (P\&D) da Agência Nacional de Energia Elétrica (Aneel), realizado com a CPFL Energia, no âmbito do Projeto Emotive (Mobilidade Elétrica CPFL). 
APÊNDICE 1

Equaçóes de busca para artigos científicos e famílias de patentes de baterias lítio-íon para veículos elétricos

\begin{tabular}{|c|c|c|c|c|c|}
\hline Data & $\begin{array}{c}\text { Base de } \\
\text { dados }\end{array}$ & Equaçóes de busca & $\begin{array}{c}\text { Campos de } \\
\text { busca }\end{array}$ & $\begin{array}{c}\text { Tipo de } \\
\text { documento }\end{array}$ & $\begin{array}{c}\text { Número } \\
\text { de } \\
\text { resultados }\end{array}$ \\
\hline $\begin{array}{l}\text { PATENTES } \\
(\mathbf{1 9 9 6 - 2 0 1 6 )} \\
26 / 10 / 19\end{array}$ & $\begin{array}{l}\text { Questel- } \\
\text { Orbit }\end{array}$ & $\begin{array}{l}\text { ((Electric Vehicle OR Electric Car OR } \\
\text { Electric Automobile OR B60L) AND } \\
\text { (lithium-ion battery OR lithium ion } \\
\text { battery OR li-ion battery OR lithium } \\
\text { battery) OR (H01M-010/052 OR } \\
\text { H01M-010/0525 OR H02J-015/00 } \\
\text { OR H01M-010/44 OR H01M- } \\
\text { 010/46)) NOT (moto OR bicycle OR } \\
\text { bike OR phone OR aircraft OR cardiac } \\
\text { OR ship OR scooter OR fly OR tricycle } \\
\text { OR refrigerator) }\end{array}$ & $\begin{array}{c}\text { Title, } \\
\text { abstract, } \\
\text { claims } \\
\text { Códigos CIP } \\
\text { e CPC }^{(1)}\end{array}$ & $\begin{array}{l}\text { Patentes } \\
\text { Ativas e } \\
\text { Inativas }\end{array}$ & 15.375 \\
\hline $\begin{array}{l}\text { ARTIGOS } \\
(\mathbf{1 9 9 6 - 2 0 1 6 )} \\
12 / 10 / 19\end{array}$ & Scopus & $\begin{array}{l}\text { (“electric car*” OR electromobility } \\
\text { OR "electric vehicle" OR "electric } \\
\text { automobile*”) AND ("battery } \\
\text { management system" OR "energy } \\
\text { storage devices") OR ("Lithium-ion } \\
\text { batter*” OR "Lithium ion batter*” } \\
\text { OR "Li-ion batter*” OR "Lithium } \\
\text { batter*” OR lithium OR "lithium ion*" } \\
\text { OR "Lithium iron phosphate*” OR } \\
\text { "LiFePO*” OR "lithium metal" OR } \\
\text { "lithium sulfur" OR "lithium air") }\end{array}$ & $\begin{array}{c}\text { Title, } \\
\text { abstract, } \\
\text { keywords }\end{array}$ & $\begin{array}{c}\text { Article, } \\
\text { Conference } \\
\text { paper, } \\
\text { Review }\end{array}$ & 5.535 \\
\hline
\end{tabular}

\begin{tabular}{|l|l|}
\hline $\begin{array}{c}\text { Códigos Internacionais } \\
\text { de Patentes (CIP) }\end{array}$ & \multicolumn{1}{c|}{ DEFINIÇÃO } \\
\hline B60L & Propulsão de veículos de propulsão elétrica \\
\hline H01M-010/44 & $\begin{array}{l}\text { Células secundárias; sua fabricação; métodos para carregar ou descarregar } \\
\text { (circuitos de carga) }\end{array}$ \\
\hline H01M-010/46 & $\begin{array}{l}\text { Células secundárias; sua fabricação; acumuladores estruturalmente combinados } \\
\text { com um aparelho de carga }\end{array}$ \\
\hline H01M-010/0525 & $\begin{array}{l}\text { Células secundárias; sua fabricação; baterias de cadeira de balanço, p. ex. baterias } \\
\text { com inserçâo de lítio ou intercalaçâo em ambos eletrodos; baterias de ín-lítio }\end{array}$ \\
\hline H01M 010/052 & Acumuladores de lítio \\
\hline H02J-015/00 & Sistemas para armazenar energia elétrica \\
\hline
\end{tabular}

Este é um artigo publicado em acesso aberto (Open Access) sob a licença Creative Commons Attribution CC-BY, que permite uso, distribuição e reprodução em qualquer meio, sem restriçôes desde que o trabalho original seja corretamente citado. 